\title{
Structure of Ni-P Melts by X-Ray Diffraction
}

\author{
B. Sedelmeyer ${ }^{\mathrm{a}}$ and S. Steeb
}

Max-Planck-Institut für Metallforschung, Seestr. 92, D-70174 Stuttgart

a Alcatel SEL, 70430 Stuttgart

Z. Naturforsch. 52a, 284-288 (1997); received November 6, 1996

X-ray diffraction was done with molten $\mathrm{Ni}_{81} \mathrm{P}_{19}\left(930^{\circ} \mathrm{C}\right)$ and with molten $\mathrm{Ni}_{68.8} \mathrm{P}_{31.2}\left(1160^{\circ} \mathrm{C}\right)$. The second peak of the structure factor and the pair correlation function of the $\mathrm{Ni}_{81} \mathrm{P}_{19}$-melt shows a shoulder, as was observed for amorphous $\mathrm{Ni}_{80} \mathrm{P}_{20}$. The first two peaks in the pair correlation function can be modelled using crystalline $\mathrm{Ni}_{3} \mathrm{P}$ besides molten $\mathrm{Ni}$. In the case of $\mathrm{Ni}_{68.8} \mathrm{P}_{31.2}$, the first peak in the pair correlation function was modelled using the distance and coordination number as in crystalline $\mathrm{Ni}_{2} \mathrm{P}$.

\section{Introduction}

With the present paper we continue the investigation of molten alloys which become amorphous by rapid cooling. Preceding investigations were concerned with Fe-B-alloys [1], Ni-B-alloys [2], and MnSi-alloys [3]. In each case the corresponding melts yielded structure factors with a shoulder on the second peak.

\section{Theoretical Fundamentals}

From the coherently scattered intensity $I_{\text {coh }}$ follows the total Faber Ziman structure factor:

$$
S^{\mathrm{FZ}}(Q)=\frac{I_{\text {coh }}(Q)-c_{1} c_{2}\left(f_{1}-f_{2}\right)^{2}}{\left(c_{1} f_{1}+c_{2} f_{2}\right)^{2}}
$$

$$
\text { with } \begin{aligned}
Q & =4 \pi \frac{\sin \theta}{\lambda}, \\
2 \theta & =\text { scattering angle, } \\
\lambda & =\text { wavelength, } \\
c_{i} \quad & \text { concentration of component } i \text { in atomic } \\
& \text { fractions, } \\
f_{i}(Q) & =\text { X-ray scattering length of component } i .
\end{aligned}
$$

The total pair correlation function follows from $S^{\mathrm{FZ}}(Q)$ according to

$$
G^{\mathrm{FZ}}(Q)=\frac{2}{\pi} \int_{0}^{\infty} Q\left[S^{\mathrm{FZ}}(Q)-1\right] \sin Q R \mathrm{~d} Q
$$

with $R=$ coordinate in real space.

Reprint requests to Prof. Dr. S. Steeb.
The corrections for polarization, anomalous dispersion, Compton scattering, and absorption as well as the normalization procedure were done as described for example in [4]. The structure factors as obtained for molten $\mathrm{Ni}_{81} \mathrm{P}_{19}$ and $\mathrm{Ni}_{68.8} \mathrm{P}_{31.2}$ in Fig. 1 do not oscillate precisely along the whole $Q$-range around unity. This behaviour may be caused by several reasons:

i) Caused by the surface tension, the specimen surface is not completely flat, which leads to a slight angle dependence of the absorption correction.

ii) During the experiment, by slight evaporation of the specimen the height of the specimen surface is varied.

iii) There is a temperature gradient between crucible and melt which may lead to the formation of a vapour interface between the crucible surface and the melt which influences the height of the specimen surface.

iv) The rise of $S(Q)$ at larger $Q$-values according to [5] possibly is caused by errors in the form factor or in the Compton scattering.

To obtain the $S^{\prime}(Q)$ factors which are given in Fig. 1 as broken lines and which show a normal behaviour, $S(Q)$ was Fourier transformed to yield $G_{t}(R)$ to which then was given the shape of

$$
G_{\mathrm{t}}(R)=-4 \pi R \varrho_{0}
$$

for $R<R_{\mathrm{c}}$. The critical radius $R_{\mathrm{c}}$ corresponds to the hard sphere diameter [6] of the atoms or to $80 \%$ of the measured atomic diameters [7], respectively. Back transformation into the $Q$-space yields the corrected run $S^{\prime}(Q)$. For $\mathrm{Ni}_{81} \mathrm{P}_{19}$ at $930^{\circ} \mathrm{C}, \varrho_{0}$ amounts to 0.0856 atoms $/ \AA^{3}$ (density $7.595 \mathrm{~g} \mathrm{~cm}^{-3}$ ) and for 


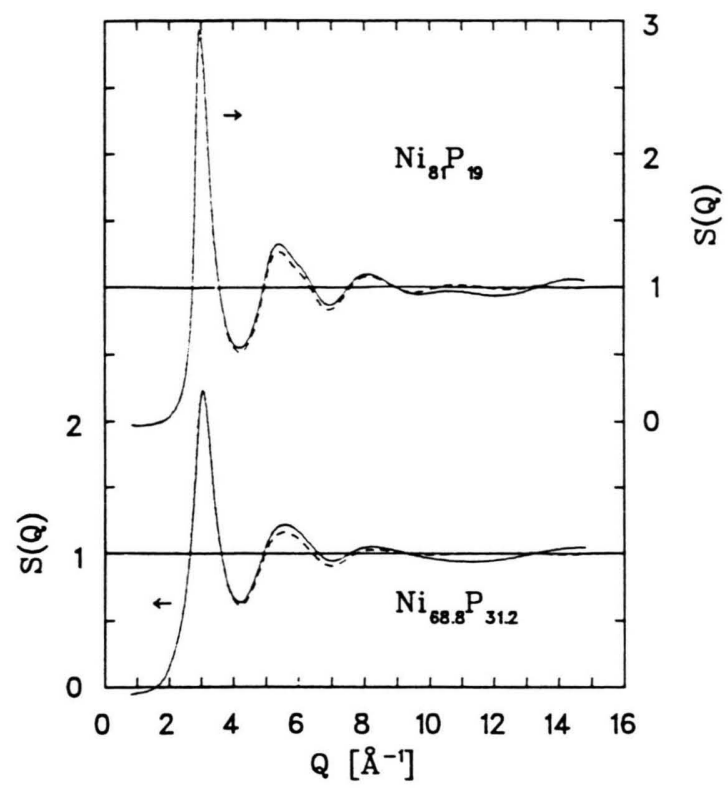

Fig. 1. Faber Ziman structure factors; X-ray diffraction (Mo-K $\alpha)$ : — as obtained $(S(Q)) ;-\ldots$ corrected $\left(S^{\prime}(Q)\right)$. Upper curves: Molten $\mathrm{Ni}_{81} \mathrm{P}_{19} ; 930^{\circ} \mathrm{C}$; Lower curves: Molten $\mathrm{Ni}_{68.8} \mathrm{P}_{31.2} ; 1160^{\circ} \mathrm{C}$.

$\mathrm{Ni}_{68.8} \mathrm{P}_{31.2}$ at $1160^{\circ} \mathrm{C}$ to 0.0811 atoms $/ \AA^{3}$ (density $6.63 \mathrm{~g} \mathrm{~cm}^{-3}$ ).

The density values were obtained for $\mathrm{Ni}_{81} \mathrm{P}_{19}$ from the density of the amorphous material which was corrected using the thermal expansion coefficient of nickel. For $\mathrm{Ni}_{68}{ }_{8} \mathrm{P}_{31.2}$ the starting density was that of crystalline $\mathrm{Ni}_{2} \mathrm{P}$.

Concerning the determination of coordination numbers in the present work the minimum-minimummethod was applied, which means that the integration in $G(R)$ always was done from the minimum at the low $R$-side of a peak to the minimum at the high $R$-side of the same peak.

\section{Experimental Fundamentals}

The diffraction experiments were done using $\mathrm{MoK} \alpha$ radiation in a $\theta-\theta$-diffractometer as described in [3]. Boronnitride-crucibles were used. At $Q$-values near the main peak, the step width $\Delta 2 \theta=0.3^{\circ}$ was used (corresponding to $\Delta Q=0.05 \AA^{-1}$ ). At $2 \theta=80^{\circ} \Delta 2 \theta$ was $0.7^{\circ}$ $\left(\Delta Q=0.08 \AA^{-1}\right)$, which yields sufficient accuracy for the investigation of molten materials. The measuring time for the region $0.75 \AA^{-1} \leq Q \leq 14.8 \AA^{-1}$ amounted to
40 minutes. As protecting atmosphere Argon (15 mbar) was used.

\section{Results and Discussion}

\subsection{Molten $\mathrm{Ni}_{81} P_{19}$}

Figure 1 shows as broken lines the corrected structure factors $S^{\prime}(Q)$ for molten $\mathrm{N}_{81} \mathrm{P}_{19}$ (upper curve) and $\mathrm{Ni}_{68.8} \mathrm{P}_{31.2}$ (lower curve). The peak positions, full widths at half maximum height, and peak heights are given in Table 1 . The second peak of $\mathrm{Ni}_{81} \mathrm{P}_{19}$ shows a weak shoulder at $6.04 \AA^{-1}$. The corresponding pair correlation functions are presented in Fig. 2, lower

Table 1. Position, height, full width at half maximum of the peaks in the structure factors of molten $\mathrm{Ni}_{81} \mathrm{P}_{19}$ at $930^{\circ} \mathrm{C}$ and $\mathrm{Ni}_{68.8} \mathrm{P}_{31.2}$ at $1160{ }^{\circ} \mathrm{C}$.

\begin{tabular}{llll}
\hline & & $\mathrm{Ni}_{81} \mathrm{P}_{19}$ & $\mathrm{Ni}_{68.8} \mathrm{P}_{31.2}$ \\
\hline 1. Maximum & Position $\left[\AA^{-1}\right]$ & 3.10 & 3.08 \\
& Height & 2.90 & 2.22 \\
& FWHM $\left[\AA^{-1}\right]$ & 0.52 & 0.75 \\
2. Maximum & Position $\left[\AA^{-1}\right]$ & 5.45 & 5.58 \\
& Height & 1.27 & 1.16 \\
& FWHM $\left[\AA^{-1}\right]$ & 1.36 & 1.48 \\
3. Maximum & Position $\left[\AA^{-1}\right]$ & 8.15 & 8.33 \\
& Height $\left[\AA^{-1}\right]$ & 1.08 & 1.03 \\
& FWHM $\left[\AA^{-1.28}\right.$ & 1.45 \\
\hline
\end{tabular}

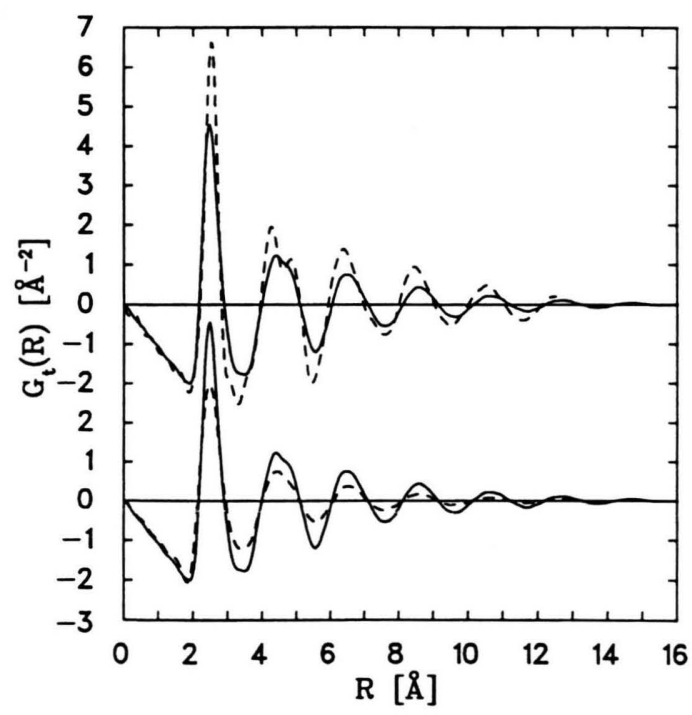

Fig. 2. Faber Ziman pair correlation functions: Upper curves: - molten $\mathrm{Ni}_{81} \mathrm{P}_{19}: 930^{\circ} \mathrm{C}$; - - - amorphous $\mathrm{Ni}_{80} \mathrm{P}_{20}$. Lower curves: $\stackrel{81}{\longrightarrow}$ molten $\mathrm{Ni}_{81} \mathrm{P}_{19} ; 930^{\circ} \mathrm{C}$; - . - molten $\mathrm{Ni}_{68.8} \mathrm{P}_{31.2} ; 1160^{\circ} \mathrm{C}$. 
curves. For molten $\mathrm{Ni}_{81} \mathrm{P}_{19}$ (solid line) the first peak lies at $2.48 \AA$ and the number of nearest neighbours amounts to 12.5 atoms. Furthermore, the second peak (4.39 $\AA$ ) shows a shoulder at $4.69 \AA$.

Up to now, a shoulder at the second peak of the structure factor or the pair correlation function, respectively, was only found with melts which form amorphous solids during rapid cooling [1-3]. Therefore we compare in Fig. 2, upper part, the total pair correlation functions of molten $\mathrm{Ni}_{81} \mathrm{P}_{19}$ and of amorphous $\mathrm{Ni}_{80} \mathrm{P}_{20}$ [8]. In [8] the partial pair correlation functions $G_{i j}(R)$ were determined. These functions add for X-rays to the total $G_{t}^{x}(R)$ according to

$$
\begin{aligned}
G_{t}^{x}(R)\left(\mathrm{Ni}_{80} \mathrm{P}_{20}\right)= & 0.778 G_{\mathrm{NiNi}}(R) \\
& +0.014 G_{\mathrm{PP}}(R)+0.208 G_{\mathrm{NiP}}(R),
\end{aligned}
$$

if one uses the X-ray form factors $f_{\mathrm{Ni}}(0)=28 \mathrm{eu}$ and $f_{\mathrm{P}}(0)=15 \mathrm{eu}$.

The run of this function is shown in the upper part of Fig. 2 as broken line. Good accordance in the positions of the first and second maximum is observed, whereas the further maxima of the melt lie at larger distances. The splitting up of the second maximum in the pair correlation function of the amorphous alloys is for the melt only indicated as a shoulder. Caused by the thermal atomic motion in the melt, the solid curve decays more rapidly with increasing $R$.

In Fig. 3 we compare the run of $G(R)$ as obtained with the melt along the two first maxima (solid line) with the run of a model structure $G_{\text {mod }}(R)$ where in the lower part crystalline $\mathrm{Ni}_{3} \mathrm{P}$ was used as model, and in the upper part a mixture of crystalline $\mathrm{Ni}_{3} \mathrm{P}$ and molten $\mathrm{Ni}$.

For melts $[9,10]$ and for amorphous alloys [11, 12], in the past it was tried to model the first peak from crystalline counterparts. For this purpose, $G_{\text {mod }}(R)$ is composed from the partial $G_{v \mu}^{\text {mod }}(R)$-functions according to

with

$$
G_{\text {mod }}(R)=\sum \frac{c_{v} f_{v}^{2}(0)}{\langle f(0)\rangle^{2}} G_{v \mu}^{\bmod }(R)
$$

$$
\begin{aligned}
G_{v \mu}^{\mathrm{mod}}(R) & =-4 \pi \varrho_{0} R+\sum_{m=1}^{k} \frac{Z_{m}}{\varepsilon_{m} R_{m} \sqrt{2 \pi}} \\
\cdot & {\left[\exp \left(-\frac{\left(R-R_{m}\right)^{2}}{2 \varepsilon_{m}^{2}}\right)-\exp \left(-\frac{\left(R-R_{m}\right)^{2}}{2 \varepsilon_{m}^{2}}\right)\right] . }
\end{aligned}
$$

$R_{m}=$ position of the $m \cdot{ }^{\text {th }}$ sphere,

$k=$ total number of spheres,

$\sigma_{m}=2.335 \cdot \varepsilon_{m}=$ half width of the sphere,

$Z_{m}=\frac{Z_{v \mu}}{c_{\mu}}=$ area of the $m \cdot{ }^{\text {th }}$ Gaussian curve.

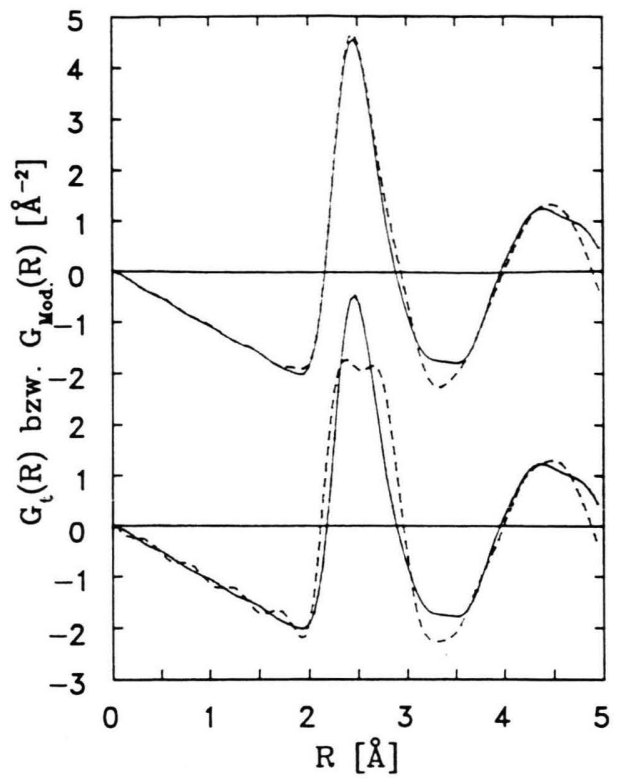

Fig. 3. Faber Ziman pair correlation functions: Upper curves: molten $\mathrm{Ni}_{81} \mathrm{P}_{19}: 930^{\circ} \mathrm{C} ;-\cdots G_{\text {mod }}(R)$ from $\mathrm{Ni}_{\text {molten }}+$ $\mathrm{Ni}_{3} \mathrm{P}$. Lower curves: - molten $\mathrm{Ni}_{81} \mathrm{P}_{19} ; 930^{\circ} \mathrm{C} ;-\cdots$ $G_{\text {mod }}(R)$ from $\mathrm{Ni}_{3} \mathrm{P}$.

The positions of the Gaussians are obtained from the distances of $\mu$-atoms to the central $v$-atom. The number $Z_{v \mu}$ of nearest neighbours at the distance $R_{m}$ is determined, and one has to keep in mind that not all $v$-atoms are surrounded at the corresponding distance $R_{m}$ by $Z_{v \mu} \mu$-atoms. The share of $v$-atoms with only $Z_{v \mu}^{\mathrm{P}} \mu$-neighbours at the distance $R_{m}$ is designed with $c_{\mathrm{v}}^{\mathrm{P}}$. Then

with

$$
Z_{v \mu}=\varepsilon_{\mathrm{P}} c_{v}^{\mathrm{P}} Z_{v \mu}^{\mathrm{P}}
$$

$$
\sum_{\mathbf{p}} c_{v}^{\mathbf{P}}=1
$$

In [13] the mean fluctuation of the squared distance of nearest neighbours is calculated for a primitive lattice. For high temperatures and uncorrelated motion of neighboured atoms follows

$$
\frac{2}{\Delta R_{I}}=\frac{18}{M \omega_{\mathrm{D}}^{2}} k_{B} \cdot T,
$$

$M=$ mass of one atom, $\omega_{\mathrm{D}}=$ Debye frequency.

According to [13], for cubic face centered lattices the empirical relationship is

$$
\omega_{\mathrm{D}}^{2}=6 \cdot 10^{-2} \frac{k_{B}}{M R_{I}^{2}} T_{m},
$$

$T_{m}=$ melting temperature of the crystal. 
This relationship is taken as approach for all kinds of crystals. Now the mean distance of nearest neighbours to their equilibrium distances is taken as half of the half width of the Gaussians in (4). According to [14] one obtains finally for the broadening $\sigma_{I}$ of nearest neighbour distances

$$
\sigma_{I} \cong 2=0.2\left[\sqrt{\frac{1}{3} \Delta R_{I}^{2}}\right]=\sqrt{R_{I}^{2} \frac{T}{T_{s}}} .
$$

If the atoms are strongly correlated, then according to [9] for the coordination spheres with larger radii follows:

$$
\sigma_{m}=0.2\left[\sqrt{R_{m}^{2} \frac{T}{T_{s}}}\right] .
$$

However, for large distances this assumption indeed is not realistic. Therefore it has been proposed in [15] to use Einstein's diffusion equation, according to which the total deviation is proportional to the root of the single deviations. In this way follows

$$
\sigma_{m}^{\prime}=0.2\left[\sqrt{R_{m} R_{I} \frac{T}{T_{s}}}\right] .
$$

This stands for a gas, and thus the real breadths will lie between $\sigma_{m}$ and $\sigma_{m}^{\prime}$.

The $G_{\bmod }(R)$-curve is Fourier-transformed and backtransformed using the same $Q_{\max }$ as in the experiment in order to produce the same truncation error as contained in the experimental curves $[8,16]$. To produce the $G_{\bmod }(R)$-curve in Fig. 3, lower part, broken line, the results of structure investigations [17] with tetragonal $\mathrm{Ni}_{3} \mathrm{P}$ were used together with the mean coordination number of nearest neighbours according to [18].

The parameters used are compiled in Table 2.

Table 2. Modelling the $G_{t}(R)$-curve for molten $\mathrm{Ni}_{81} \mathrm{P}_{19}$;

\begin{tabular}{|c|c|c|c|c|c|c|c|}
\hline & \multicolumn{3}{|c|}{$\mathrm{Ni}_{3} \mathrm{P}$} & & \multicolumn{3}{|c|}{$\mathrm{Ni}$ molten $+\mathrm{Ni}_{3} \mathrm{P}$} \\
\hline & $Z$ & $R[\AA]$ & $\sigma[\AA]$ & & $Z$ & $R[\AA]$ & $\sigma[\AA ̊]$ \\
\hline \multirow[t]{2}{*}{$Z_{\mathrm{NiP}}$} & 3.0 & 2.28 & 0.30 & $Z_{\mathrm{NiP}}$ & 2.11 & 2.33 & 0.40 \\
\hline & & & & $\begin{array}{l}Z_{\mathrm{NiNi}} \\
\text { (molten) }\end{array}$ & 3.72 & 2.46 & 0.38 \\
\hline$Z_{\mathrm{NiNi}}$ & 10 & 2.68 & 0.55 & $\begin{array}{l}Z_{\mathrm{NiNi}} \\
\left(\mathrm{Ni}_{3} \mathrm{P}\right)\end{array}$ & 7.04 & 2.75 & 0.59 \\
\hline$Z_{\mathrm{PP}}$ & 4.0 & 3.44 & 0.60 & $Z_{\mathrm{PP}}$ & 4.0 & 3.53 & 0.60 \\
\hline
\end{tabular}
$930^{\circ} \mathrm{C}$; parameters used, namely coordination numbers $Z$, atomic distances $R$, and half widths $\sigma$.
The solid and broken lines in the lower part of Fig. 3 do not show good accordance. Therefore another approach was used: Molten $\mathrm{Ni}_{81} \mathrm{P}_{19}$ contains $6 \%$ more nickel than $\mathrm{Ni}_{3} \mathrm{P}$, i.e. $\mathrm{Ni}_{75} \mathrm{P}_{25}$. Therefore the second model, the parameters of which also are presented in Table 2, contains besides $\mathrm{Ni}_{3} \mathrm{P}$ molten $\mathrm{Ni}$ [4]. In Fig. 3, upper curves, the result is presented and yields very good agreement between experiment and model. This means that molten $\mathrm{Ni}_{81} \mathrm{P}_{19}$ shows a segregation tendency in the sense that $\mathrm{Ni}_{3} \mathrm{P}$ and $\mathrm{Ni}$ coexist in a similar way as AuCs and Au or Cs, respectively, in molten Au-Cs-alloys [19]. Thus, for molten $\mathrm{Ni}_{81} \mathrm{P}_{20}$ in a similar way as for amorphous $\mathrm{Ni}_{80} \mathrm{P}_{20}$ [20] and as for molten Au-Cs-alloys the effect of small angle scattering is to be expected.

\subsection{Molten $N i_{68.8} P_{31.2}$}

In Fig. 1, lower curves, as broken line the corrected total Faber Ziman $S^{\prime}(Q)$ is presented as obtained with molten $\mathrm{Ni}_{68.8} \mathrm{P}_{31.2}$. The position of the first peak is the same as for molten $\mathrm{Ni}_{81} \mathrm{P}_{19}$, but with $0.75 \AA^{-1}$ it is broader than the $\mathrm{Ni}_{81} \mathrm{P}_{19}$-peak with $0.52 \AA^{-1}$. The height is 2.22 compared to 2.9 in the upper curve.

If we calculate the weighting factors for the case of molten $\mathrm{Ni}_{68.8} \mathrm{P}_{31.2}$ analogous to (4), then the weighting factor is smaller for the $\mathrm{Ni}-\mathrm{Ni}$, but larger for the Ni-P and P-P-correlations. Thus, for nearly the same atomic distribution in molten $\mathrm{Ni}_{81} \mathrm{P}_{19}$ and molten $\mathrm{Ni}_{68.8} \mathrm{P}_{31.2}$ indeed a broadening of the first peak in the structure factor and in the pair correlation function is to be expected. The fact that the Ni-Ni correlation has a smaller weighting factor explains why the first peak in molten $\mathrm{Ni}_{68.8} \mathrm{P}_{31.2}$ is smaller [4].

There is no shoulder at the second peak, neither in the structure factor nor in the pair correlation function of Figure 4. Also up to now no amorphous phase with a corresponding composition could be produced.

The concentration ratio of $\mathrm{Ni}_{68.8} \mathrm{P}_{31.2}$ and $\mathrm{Ni}_{2} \mathrm{P}$, i.e. $\mathrm{Ni}_{66.6} \mathrm{P}_{33.3}$, is nearly the same, and therefore modelling of the first two peaks of the pair correlation function in Fig. 4 was done using the crystal structure of hexagonal $\mathrm{Ni}_{2} \mathrm{P}$ [21]. The model has to be fitted to the first coordination sphere. All distances had to be enlarged, as in the case of $\mathrm{Ni}_{3} \mathrm{P}$, by $2.5 \%$. The broken line in Fig. 4 shows the model pair correlation function. The number of nearest neighbours amounts to 11.5 atoms in the melt and to 11.7 in $\mathrm{Ni}_{2} \mathrm{P}$. Apparently the structure of the melt depends on the structure of the corresponding or a directly neighboured phase. Table 3 contains the parameters used for the fit. 


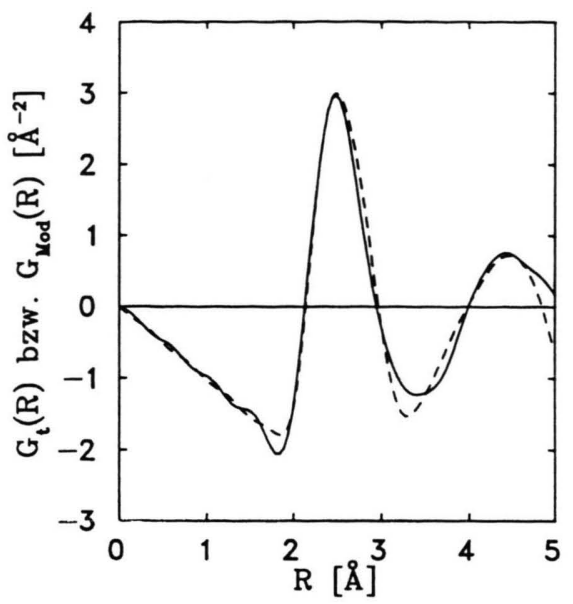

Fig. 4. Faber Ziman pair correlation functions; - molten $\mathrm{Ni}_{68.8} \mathrm{P}_{31.2} ; 1160^{\circ} \mathrm{C} ;-\cdots G_{\text {mod }}(R)$ from $\mathrm{Ni}_{2} \mathrm{P}$.

\section{Conclusions}

Molten $\mathrm{Ni}_{81} \mathrm{P}_{19}$ at $930^{\circ} \mathrm{C}$ and molten $\mathrm{Ni}_{68.8} \mathrm{P}_{31.2}$ at $1160^{\circ} \mathrm{C}$ were investigated using $\mathrm{X}$-ray diffraction in a $\theta-\theta$ diffractometer. Total structure factors and pair correlation functions were obtained in which for molten $\mathrm{Ni}_{81} \mathrm{P}_{19}$ always the second peaks shows a

[1] E. Nold, G. Rainer-Harbach, P. Lamparter, and S. Steeb, Z. Naturforsch 38a, 325 (1983).

[2] E. Nassif, P. Lamparter, B. Sedelmeyer, and S. Steeb, Z. Naturforsch 38 a, 1098 (1983).

[3] E. Nassif, P. Lamparter, B. Sedelmeyer, and S. Steeb, Z. Naturforsch 38 a, 1093 (1983).

[4] B. Sedelmeyer, Thesis, University of Stuttgart (1985).

[5] H. Ruppersberg and H. J. Seemann, Z. Naturforsch 21 a, 9820 (1966).

[6] A. Rahman, J. Chem. Phys. 42, 3540 (1965).

[7] J. L. Yarnell, M. J. Katz, R. G. Wentzel, and S. H. Koenig, Phys. Rev. A7, 2130 (1973).

[8] P. Lamparter and S. Steeb, Proc. RQ5, edited by S. Steeb and H. Warlimont, Elsevier Science Publishers BV (1985), p. 459.

[9] N. A. Vatolin and E. A. Pastuhov: 4th Japan-USSR Joint Symposium on Phys. Chem. of Metallurgical Processes, (1973), pp. 1-12.

[10] A. Bizid, A. Defrain, R. Bellissent, and G. Tourand, J. de Physique 39, 554 (1978).
Table 3. Modelling of molten $\mathrm{Ni}_{68.8} \mathrm{P}_{31.2}$. Parameters for hexagonal $\mathrm{Ni}_{2} \mathrm{P}[21]$.

\begin{tabular}{llll}
\hline & $Z$ & $R[\AA]$ & $\sigma[\AA]$ \\
\hline$Z_{\mathrm{PNi}}$ & 4 & 2.32 & 0.40 \\
$Z_{\mathrm{PNi}}$ & 2 & 2.44 & 0.50 \\
$Z_{\mathrm{PNi}}$ & 1 & 2.65 & 0.65 \\
$Z_{\mathrm{NiNi}}$ & 7 & 2.67 & 0.65 \\
$Z_{\mathrm{PNi}}$ & 2 & 2.70 & 0.65 \\
\hline
\end{tabular}

shoulder just as in amorphous $\mathrm{Ni}_{80} \mathrm{P}_{20}$. The first two peaks in the total pair correlation function were modelled, using for the $\mathrm{Ni}_{81} \mathrm{P}_{19}$ melt crystalline $\mathrm{Ni}_{3} \mathrm{P}$ plus molten $\mathrm{Ni}$ as a modelling substance. The good accordance shows up a segregation tendency $\left(\mathrm{Ni}_{3} \mathrm{P}\right.$ besides $\mathrm{Ni}$ ) in molten $\mathrm{Ni}_{81} \mathrm{P}_{19}$. For molten $\mathrm{Ni}_{68.8} \mathrm{P}_{31.2}$ a good fit could be obtained using the shortest atomic distances and coordination numbers as in crystalline $\mathrm{Ni}_{2} \mathrm{P}$.

The results show that the chemical short range order, i.e. the number and kind of nearest neighbours as well as their mutual distances is practical the same for a binary alloy in the molten state, in the crystalline state and the amorphous state of the Ni-P-alloys under consideration.

[11] J. Dixmier, K. Doi, and A. Guinier, Phys. Non Cryst. Solids, ed. by J. A. Prins, North Holland, Amsterdam 1965 , p. 67.

[12] P. Lamparter, W. Sperl, E. Nold, G. Rainer-Harbach, and S. Steeb, Proc. 4th Int. Conf. Rapidly Quenched Metals, Sendai 1981, p. 343.

[13] G. Leibfried: Handbuch der Physik, Springer-Verlag VII, Berlin (1955), p. 260.

[14] H. Ruppersberg, Z. Phys. 189, 292 (1966).

[15] O. Kratky, Phys. Z. 34, 482 (1933).

[16] W. Sperl, Thesis, University of Stuttgart (1982).

[17] S. Rundqvist, E. Hassler, and C. Lundvik, Acta Chem. Scand. 16, 242 (1962).

[18] Y. Waseda and J. M. Toguri, Z. Naturforsch 32 a, 1506 (1977).

[19] W. Martin, W. Freyland, P. Lamparter, and S. Steeb, J. Phys. Chem. Liq. 10, 61 (1980).

[20] K. Schild, Thesis, University of Stuttgart (1985).

[21] K. Schubert, Kristallstrukturen zweikomponentiger Phasen, Springer-Verlag, Berlin 1964. 